\title{
DHA in Pregnancy Benefits Child Development
}

\begin{abstract}
A review of: Helland IB, Smith L, Saarem K, et al. 2003 Maternal supplementation with very-long-chain fatty acids during pregnancy and lactation augments children's IQ at 4 years of age. Pediatrics 2003 111:e39-e44; and Myers GJ,

Davidson PW, Cox C, et al. 2003 Prenatal methylmercury exposure from ocean fish consumption in the Seychelles child development study. Lancet 361:1686-1692
\end{abstract}

$\mathrm{T}$ HE FUNCTIONAL ROLE of docosahexaenoic acid (DHA: C22:6 n-3) for the structural and functional development of young infants seems to be at least partly established. During pregnancy DHA is preferentially transferred from the mother to the foetus, particularly in the last trimester of pregnancy, and impairments in this passage are associated with intrauterine growth retardation (1). In infancy, brain DHA levels are higher if the infant has some dietary sources of DHA (for instance, human milk) and neurodevelopmental scores are associated with DHA levels in body pools represented by blood indices (2). Recently, DHA intake in early infancy has also been associated with lower blood pressure values at 5 years of age (3).

On the other hand, mercury, particularly methylmercury, is an established worldwide environmental pollutant with known toxicity in humans. Recent data suggest that fetal exposure to methylmercury at high levels results in subtle decrements in several mea-
Carlo Agostoni, Elvira Verduci

sures of neurologic development at 7 years of age (4).

Human consumption of fish provides a unique dietary source of DHA and methylmercury. DHA is stored primarily in ocean fish species found in deep sea levels, while mercurials in seafood are mainly derived from pollutants. What is the net benefit of eating fish on infants' neural development? Enrichment of maternal diet with DHA sources has been hypothesized to have beneficial effects for enhancing fetal and infant development in spite of the lack of direct evidence (2). Conversely, a consumer advisory from the Food and Drug Administration has recommended that pregnant women avoid fish species with the highest average amounts of methylmercury (5).

A recent study from the University of Oslo, shows a developmental advantage at 4 years of age for children born to breastfeeding mothers supple- mented with cod liver oil from the 18th week of pregnancy to 3 months after delivery, compared with a placebosupplemented group (6). Moreover, other investigators reported the results from the Seychelles child development study, showing that most domains of cognitive performance of 9-year-old children were not associated with methylmercury concentrations in their mothers' hair at the end of pregnancy (7). The concentrations of methylmercury in fish from the Seychelles were reported to be similar to that in fish consumed in most of the world.

On balance, the existing evidence suggests that methylmercury exposure from fish consumption during pregnancy may have no measurable detrimental cognitive or behavioral effects in later childhood. It may be that DHA could have a neuroprotective effect, as suggested by the association of better neurofunctional indices at 12 months and higher blood DHA for hyperphenylalaninemic infants before diagnosis, when their blood levels of phenyl- 
alanine are well beyond the limits of safety for the brain (8). Nonetheless, data of Helland et al show a positive effect on infant development with a daily consumption of greater than 1 gram DHA per day, a limit almost impossible to reach by just eating fish (unless consumed in quite large and unusual daily amounts).

In conclusion, although the safety of eating fish during pregnancy is not firmly established, there is now evidence that DHA supplementation during pregnancy may be beneficial.

1. Cetin I, Giovannini N, Alvino G, Agostoni C, Riva E, Giovannini M, Pardi G 2002 Intrauterine growth restriction is associated with changes in polyunsaturated fatty acid fetal-maternal relationships. Pediatr Res 52:750-755

2. Koletzko B, Agostoni C, Carlson SE, Clandinin T, Hornstra G, Neuringer M, Uauy R, Yamashiro Y, Willatts P 2001 Long-chain polyunsaturated fatty acids and perinatal development. Acta Paediatr 90:460-464

3. Forsyth JS, Willatts P, Agostoni C, Bissenden J, Casaer P, Boehm G 2003 Long chain polyunsaturated fatty acid supplementation in infant formula and blood pressure in later childhood: follow up of a randomized controlled trial. BMJ 326:953-957

4. Grandjean P, White RF, Weihe P, Jorgensen PJ 2003 Neurotoxic risk caused by stable and variable exposure to methylmercury from seafood. Ambul Pediatr 3:18-23

5. Bolger PM, Schwetz BA 2002 Mercury and health. N Engl J Med 347:1735-1736

6. Helland IB, Smith L, Saarem K, Saugstad OD, Drevon CD 2003 Maternal supplementation with very-long-chain fatty acids during pregnancy and lactation augments children's IQ at 4 years of age. Pediatrics 111:e39-e44
7. Myers GJ, Davidson PW, Cox C, Shamlaye CF, Palumbo D, Cernichiari E, Sloane-Reeves J, Wilding GE, Kost J, Huang LS, Clarckson TW 2003 Prenatal methylmercury exposure from ocean fish consumption in the Seychelles child development study. Lancet 361:1686-1692

8. Agostoni C, Verduci E, Massetto N, Radaelli G, Riva E, Giovannini M 2003 Plasma long-chain polyunsaturated fatty acids and neurodevelopment through the first 12 months of life in phenylketonuria. Dev Med Child Neurol 45:257-261

Department of Pediatrics

San Paolo Hospital

8 Via A di Rudini

20142 Milan, Italy

e-mail: agostoc@tin.it

DOI: 10.1203/01.PDR.0000088365.16983.A8 